\title{
PARA UMA CONCETUALIZAÇÃO ALTERNATIVA DE ACCOUNTABILITY EM EDUCAÇÃO
}

\author{
Almerindo Janela Afonso*
}

\begin{abstract}
RESUMO: Nas últimas duas ou três décadas, a problemática da accountabilty tem sido enclausurada nas lógicas do pensamento único, neoconservador e neoliberal. Torna-se, por isso, necessário lembrar que há outras alternativas. Neste sentido, este texto adota uma abordagem crítica e revisita brevemente o conceito de accountability (ou seja, a interação entre avaliação, prestação de contas e responsabilização), no sentido de chamar a atenção para configurações que sejam mais democráticas e progressistas. Por referência a esta mesma problemática, pontuam-se também algumas tendências em curso em Portugal e outros países europeus.
\end{abstract}

Palavras-chave: Políticas educacionais. Exames e testes estandardizados. Accountability neoliberal e neoconservadora. Accountability alternativa.

\section{TO AN ALTERNATIVE APPROACH OF ACCOUNTABILITY ON EDUCATION}

ABSTRACT: In the last two or three decades, the issue of accountability has been enclosed in the logic of the neoconservative and neoliberal single thought. It is therefore necessary to show that there are others alternatives. In this regard, this paper adopts a critical approach and briefly revisits the concept of accountability (that is, the interaction between evaluation, answerability and enforcement) in order to draw attention to the need for models that could be more democratic. By reference to this same question, the author indicates some trends underway in Portugal and other European countries.

Key words: Educational policies. Examinations and standardised tests. Neoliberal and neoconservative accountability. Alternative accountability. * Doutor em Educação e pesquisador do Centro de Investigação em Educação da Universidade do
Minho (Portugal). E-mail: ajafonso@ie.uminho.pt 


\section{POUR UNE AUTRE CONCEPTUALISATION D E L'ACCOUNTABILITY}

RÉSUMÉ: Dans les deux ou trois dernières décennies, la question de l'accountabilty a été cloîtrée dans les logiques de la pensée unique, néoconservatrice et néolibérale. Il faut donc que l'on se souvienne qu'il y a d'autres alternatives. En ce sens, ce texte adopte une approche critique et revisite sommairement la notion de l'accountabilty (c'est-à-dire l'interaction entre l'évaluation, le rendu de comptes et la responsabilisation) afin d'attirer l'attention sur des configurations qui soient plus démocratiques et progressistes. Par référence à cette même question, on souligne aussi certaines tendances en cours au Portugal et en autres pays européens.

Mots-clés: Politiques d'éducation. Examens et tests standardisés. Accountability néolibérale et néoconservatrice. Accountability alternative.

\section{Introdução}

A referência frequente à necessidade de implementação de certas formas de accountability transformou-se numa panaceia (ou mesmo num fetiche) pelo facto de a avaliação, a prestação de contas e a responsabilização serem, supostamente, capazes de, por si sós, satisfazer as expetativas de grupos e setores sociais aparentemente desejosos de resolver os défices e problemas de qualidade da educação pública. Em muitas situações, abstraída do contexto de retração profunda do Estado e do recuo dos direitos sociais, económicos e culturais, esta qualidade - que em vez de ser uma "qualidade negociada" (ver, por exemplo, Freitas, 2005, 2007), é, ao invés, assumida como axiologicamente neutra, despolitizada em termos de princípios e fins educacionais e humanos, e nunca definida na sua complexidade institucional ou organizacional (Sá, 2008; Esteban \& Afonso, 2010) -, traduz-se, no senso comum, de forma redutoramente naturalizada, ao mesmo tempo em que a educação (enquanto bem público) continua a ser ressignificada e redimensionada, no embate com orientações e políticas concretas do conservadorismo neoliberal - o qual, aliás, transformou-se nas últimas décadas numa espécie de vírus (Amin, 2005) que se espalha para além das fronteiras nacionais dos países que o criaram ou fizeram emergir.

Em grande parte dos discursos marcados por este viés político-ideológico, o significado do vocábulo accountability indica frequentemente uma forma hierárquico-burocrática ou tecnocrática e gerencialista de prestação de contas que, pelo menos implicitamente, contém e dá ênfase a consequências ou imputações negativas e estigmatizantes, as quais, não raras vezes, consubstanciam formas autoritárias de responsabilização das instituições, organizações e indivíduos. Aliás, mesmo quando estas caraterísticas são menos vincadas, o certo é que a representação social que acentua o seu carácter punitivo tem sido um importante obstáculo à concetualização 
de formas mais avançadas e alternativas de accountability. Por isso, como Ranson (2003) chama a atenção, não se pode esquecer que a accountability é muitas vezes sentida como um anátema.

Entre muitos outros casos, a lei No Child Left Behind, aprovada nos EUA na era de George W. Bush, é disso um exemplo paradigmático. Neste caso, a accountability baseia-se em resultados de testes estandardizados de alto impacto (high-stakes testing), os quais fundamentam sanções negativas e outras intervenções das autoridades estaduais que são dirigidas tanto a distritos escolares, como a estabelecimentos de ensino, professores e estudantes. São, por isso, testes que têm importantes implicações para os avaliados, nomeadamente quando impedem o acesso a certificados e graus académicos, podendo, em relação às escolas, originar processos que vão da advertência pelos maus resultados apresentados até ao seu encerramento quando estas não atingem determinados níveis ou padrões de desempenho. Assim, o uso de high-stakes testing significa, em última instância, que os resultados dos testes estandardizados constituem o fator decisivo para a tomada de decisões cruciais para a vida dos sujeitos e das instituições de ensino.

Por estas razões, e também pelo facto de a sua aplicação poder dar origem a efeitos espúrios e consequências não desejáveis (Afonso, 2009), os testes estandardizados de elevado impacto têm sido fortemente criticados por diversos setores sociais, por importantes responsáveis políticos e especialistas da educação (entre outros, Ravitch, 2010a), bem como por prestigiadas associações científicas (a este propósito, ver a organização norte-americana FairTest). ${ }^{1}$ Ao contrário do que é anunciado, paradoxalmente "a verdadeira vítima desta obstinação é a qualidade de ensino" (Ravitch, 2010b, p. 9).

Todavia, muitas destas questões não são novas. Com efeito, o movimento de $a c$ countability teve uma forte manifestação nos EUA já no início dos anos de 1970, podendo a sua história ser contada a partir mesmo de outras manifestações anteriores. Se já nessa altura a accountability se tornara "uma obrigação moral e uma cruzada" (House, 1975, p. 74), no período que corresponde à administração de George W. Bush a retórica e justificação parecem ser idênticas, ainda que haja algo de novo nesta última reforma neoconservadora, nomeadamente no que diz respeito a um maior "intervencionismo federal num sistema largamente descentralizado e a extensão do regime de sanções contra as escolas públicas" (Normand, 2008, p. 53). Saliente-se, aliás, que, ao contrário das expectativas iniciais, a administração Barack Obama manteve a Lei No Child Left Behind e o próprio presidente americano tem apoiado vivamente o debate em torno do pagamento diferenciado aos professores na base do mérito.

Neste sentido, o que é pertinente ressaltar é que não apenas estas agendas não foram ultrapassadas como, no que diz respeito mais especificamente à accountability 
em educação, elas continuam a estruturar-se (também em muitos outros contextos, hoje em dia), com os mesmos ou idênticos dispositivos de há mais de quatro décadas, quer nos EUA, quer noutros países (avaliação externa baseada em testes estandardizados estaduais e/ou nacionais, explicações privadas para superar défices da escola pública, publicitação dos resultados e rankings escolares, responsabilização das escolas e dos gestores, avaliação e responsabilização de professores fortemente conectadas com os resultados académicos dos alunos, entre outros). ${ }^{2}$

\section{A experiência europeia e portuguesa: alguns apontamentos}

Em alguns países europeus, a adoção e valorização de dispositivos de $a c$ countability em educação têm vindo a consolidar-se e, tal como acontece no contexto norte-americano, "na atualidade, talvez a principal finalidade dos testes e exames externos seja precisamente a accountabilty" (Stobart, 2010, p. 38). Esta afirmação é indiscutivelmente válida para o caso da Inglaterra. Neste país, por exemplo, na sequência sobretudo da viragem protagonizada pelo partido conservador, liderado por Margaret Thatcher nos anos de 1980, as políticas recolocaram no sistema educativo a centralidade dos exames nacionais (Afonso, 1999), e isso não foi de modo algum indiferente aos objetivos e interfaces explícitos de prestação de contas e de responsabilização. Mesmo em anos mais recentes, fazendo de algum modo ressurgir controvérsias com precedentes históricos, voltaram os debates em torno do pagamento aos professores na base dos resultados dos alunos (merit pay ou performance pay system), a propósito dos quais muitas das críticas têm chamado a atenção para as consequências nefastas deste sistema. ${ }^{3} \mathrm{E}$ pouquíssimos argumentos parecem ter sido levados em boa conta ou ter refreado suficientemente as agendas mais ortodoxas, apesar de, já no século XIX, nomeadamente na Inglaterra, a política de pagamento por resultados ter sido "um exemplo revelador das distorções provocadas pelo uso da avaliação com fins de accountability" (Stobart, 2010, p. 40).

No âmbito mais amplo da União Europeia, a accountability só mais recentemente passou a ser um termo recorrente nos textos oficiais orientadores e nos discursos políticos, o que ocorreu de forma relativamente sincrónica em associação com os conceitos de bom governo, boa governação e governança democrática (democratic governance). Um dos referentes importantes a este propósito é sem dúvida o Livro Branco sobre "Governança Europeia", publicado pela Comissão das Comunidades Europeias (CEC) em 2001. Neste documento são assumidos cinco princípios nos quais se deve basear uma boa governança: "abertura, participação, accountability, eficácia e coerência", concluindo-se ainda que "cada um destes princípios é fundamental para a instauração de uma governança mais democrática". ${ }^{4}$ Também no interior da União Europeia têm sido experimentadas novas formas de relação, colaboração e avaliação, 
por vezes interpretadas como constitutivas de uma espécie de aprendizagem mútua, as quais articulam distintos patamares e níveis. A este propósito, é de referir o chamado método aberto de coordenação que, em muitas das suas dimensões, incorpora princípios e técnicas idênticos aos da nova gestão pública, nomeadamente na definição de normas e indicadores e no estabelecimento de comparações e procedimentos periódicos de avaliação e monitorização (cf. Harlow, 2002, p. 189).

Por efeito do Programme for International Student Assessment (Pisa), dentro e para além do espaço europeu, a obsessão pela comparação é sobretudo visível no que diz respeito à educação. A este propósito, o Pisa é um claro exemplo do atual comparativismo internacional que tem sido potenciado e tornado mais eficaz (social e politicamente) pela imagem de credibilidade que este programa alcançou, constituindo-se, igualmente, como uma forma de regulação soft bem-sucedida (Costa, 2011; Carvalho, 2011).

Aliás, do meu ponto de vista, nos anos de 1990, com a centralidade crescente de organizações internacionais, como a OCDE, entrámos numa nova fase de desenvolvimento do Estado-avaliador e, neste novo contexto, dezenas de Estados, independentemente das suas orientações político-ideológicas e, em grande medida, acima delas, participam ou interferem ativamente, de formas diversas, na construção de um sistema de avaliação comparada internacional, cujas consequências, mais imediatas, permitem vincular e legitimar muitos discursos e muitas políticas nacionais para a educação e a formação.

A grande valorização atual do Pisa não retira, no entanto, visibilidade e importância aos exames nacionais, os quais existem em diversos países da Europa com objetivos não coincidentes. Alguns desses objetivos decorrem da realização de provas estandardizadas, cujos resultados permitem a comparação e emulação entre escolas, ou fundamentam medidas para a sua responsabilização, servindo ainda como critério para a avaliação do próprio sistema educativo. Como se pode ler em documento elaborado pela Rede Eurydice (2010, p. 19), para além de se constituírem como indicadores das políticas e práticas educativas, "os resultados dos exames são utilizados juntamente com outros parâmetros como indicadores da qualidade do ensino e, menos frequentemente, do desempenho dos professores". Todavia, no que diz respeito à accountability, e em comparação com alguns países não europeus como os EUA ou o Canadá, "só raramente os resultados dos exames na Europa servem de instrumento de responsabilização mediante sanções e recompensas” (ibid., p. 61). Ou seja, os exames, na maioria dos casos, integram-se apenas em formas parcelares de accountabilty (Afonso, 2010a).

Há, mesmo assim, uma clara tendência na maior parte dos países europeus para um maior controlo sobre a ação didático-pedagógica dos professores, os quais, 
por um lado, passaram a ser menos monitorizados pelos departamentos ou órgãos oficiais de inspeção em relação aos processos de ensino, mas, por outro, têm agora de prestar contas essencialmente em relação aos resultados escolares mensuráveis. $\mathrm{Na}$ realidade, os professores e as escolas estão submetidos de forma crescente a uma prestação de c]ontas múltipla ("multi-accountability"), não apenas em relação aos ministérios da educação, às autarquias ou administrações locais e à comunidade educativa, mas também aos pais e outros responsáveis pela educação (Eurydice, 2007).

Em Portugal, considerando as orientações e políticas nacionais mais recentes, a problemática da accountability tem vindo também a tornar-se mais presente (Santiago et al., 2012), mas ainda de uma forma oscilante e pouco consistente. No que diz respeito à educação e outras áreas da governação, a atual coligação neoliberal e neoconservadora no poder em Portugal preconiza a criação de uma "cultura da transparência" e de "responsabilização pelos resultados" e uma "generalização da avaliação nacional", a qual, neste caso, vai passar a abarcar também níveis de ensino mais elementares, como acontecerá em decorrência da recente aprovação da introdução de provas finais já no $4^{\circ}$ ano do ensino básico (Portugal, Programa do XIX Governo Constitucional, 2011). Uma vez mais, tudo se resume aos exames e aos seus resultados, indo de encontro a um apelo saudosista de alguns setores interessados no reforço, cada vez mais precoce, da seletividade classista que vigorou noutros tempos na escola pública. Aliás, o próprio sistema de avaliação é instável e fragmentário, não respeitando especificidades, nem evitando efeitos indesejáveis decorrentes das interfaces entre avaliação de escolas, avaliação de professores e avaliação de alunos. Assim, a tendência avaliocrática nos últimos anos tem sido a de sobrevalorizar os resultados (mensuráveis) da avaliação dos alunos, interferindo redutoramente, de formas várias e nem sempre explícitas, nas outras duas avaliações (das escolas e dos professores).

E, ao contrário do que diz o último relatório da OCDE (Santiago et al., 2012), não me parece que em Portugal se tenha ido mais longe do que induzir formas parcelares de accountability (Afonso, 2010a e 2010b) - o que tem passado sobretudo pelo pilar da avaliação (com exames, provas nacionais, avaliações externas das escolas e avaliação do desempenho docente) e (menos) pelo pilar da prestação de contas (através de informação ou justificação relativamente aos resultados da avaliação dos alunos e das escolas). Mas continua a adiar-se (ou a não se clarificar de forma consistente) a questão das consequências da avaliação, inerente ao pilar da responsabilização. Assente em formas de avaliação desconexas e contraditórias, e numa prestação de contas condicionada pela indução de lógicas de quase-mercado educacional ou por razões gestionárias e pragmáticas, é altamente problemático pensar o pilar da responsabilização, com valores e princípios democráticos, quando não há sequer (e 
com a crise económica ainda será mais improvável) um rumo claramente definido sobre o que deveriam ser (e com que recursos públicos deveriam contar) as políticas concretas para a melhoria das escolas, melhoria da ação profissional dos educadores e professores e melhoria dos resultados dos alunos.

\section{Repensar a accountability: das formas inteligentes às formas mais democráticas}

Não há nenhuma razão para não pensarmos e escrevermos no sentido de contribuir para resgatar criticamente a problemática da accountabilty, enclausurada atualmente nas lógicas do pensamento único, neoconservador e neoliberal. Torna-se necessário, por isso, mostrar que há outras alternativas que podem e devem ser reflexivamente consideradas e postas em prática, sobretudo por terem maior densidade teórico-concetual e/ou pertinência política e educacional. Por não ser possível aprofundar, neste momento, essas alternativas, farei a seguir uma descrição muito breve e tópica de dois contributos.

Stobart (2010), por exemplo, propõe o que designa de "accountability inteligente". Trata-se de uma forma de prestação de contas e de responsabilização fundamentada em valores, promotora de confiança nos professores e nas escolas, mais construtiva do que a dos modelos atuais (cuja dominância é negativamente sancionatória), e que se baseia não exclusivamente em exames externos, mas em procedimentos e instrumentos de avaliação múltiplos, mais sofisticados e diversificados. Além disso, os objetivos ou metas educacionais a atingir deverão ser mais realistas, evitando a ambição pragmática e imediatista dos governantes que, frequentemente, os impõem desconsiderando ou desconhecendo condições, tempos, possibilidades, constrangimentos, recursos materiais, escolas, professores e comunidades educativas efetivamente existentes. É também um modelo de accountability que respeita margens importantes de autonomia dos atores e das organizações educativas, que pressupõe um tempo mais longo para propiciar as mudanças e verificar os seus resultados, que inclui todos os grupos sociais de alunos e que implica também a garantia da própria fiabilidade do modelo de accountability (Stobart, 2010).

Do meu ponto de vista, para pensar a problemática da accountability de forma alternativa ao pensamento atualmente dominante, é necessário começar por chamar a atenção para a necessidade de desenvolver uma "concepção de accountability mais ampla, fundamentada e complexa do ponto de vista teórico-metodológico, político e axiológico" (Afonso, 2010a p. 157). Neste sentido, na continuidade do trabalho anterior, reitero aqui a ideia de uma configuração de accountability democraticamente avançada, incluindo a avaliação, a prestação de contas e a responsabilização, pressupondo 
relações e conexões abertas, problematizáveis e susceptíveis de se aperfeiçoarem ou reconstituírem, e que se legitimem ou se sustentem em valores e princípios essenciais: a cidadania crítica, a participação, o empowerment, o direito à informação, a transparência e a justiça, entre outros. Abordarei apenas alguns destes aspetos.

A primeira dimensão ou pilar da accountability deve ser a avaliação. Mas a avaliação é ela própria referenciável a diferentes modelos e teorias, os quais são muito heterogéneos (e até, por vezes, contraditórios) nos seus pressupostos, nos seus objetivos e na sua concretização. Do meu ponto de vista, uma concetualização progressista e alternativa de accountability exige igualmente abordagens democráticas de avaliação, como a avaliação democrática deliberativa (deliberative democratic evaluation), proposta, por exemplo, por autores como Howe e Ashcraft (2005). Esta abordagem carateriza-se, de forma genérica, por assentar em três princípios: a inclusão, o diálogo e a deliberação.

Para estes autores, o princípio da inclusão requer que sejam tidos em consideração e participem de forma ativa e comprometida todos os grupos com interesses significativos (stakeholders). Dito de outro modo, uma "inclusão passiva" não é suficiente para assegurar que as vozes incluídas venham a ser genuínas e se empenhem numa clara relação dialógica de avaliação. Neste aspeto, aliás, o princípio do diálogo pode concretizar-se ou num mero registo elucidativo (limitando-se a clarificar os pontos de vista dos participantes) ou, pelo contrário, ser um "diálogo crítico", sujeitando-se, para além dessa clarificação, a um escrutínio racional, congruente com uma atitude cognitiva apoiada em evidências e na qual os participantes e avaliadores se envolvam de forma colaborativa, tendo em conta os valores em confronto e fazendo emergir conclusões argumentadas e defensáveis (Howe \& Ashcraft, 2005). Como escreve também Ryan (2005) a este propósito, o diálogo é a forma mais adequada de expressão dos diferentes interesses, ideias e opiniões. Quer no interior de cada um dos grupos interessados no processo de avaliação, quer entre grupos, o diálogo é particularmente valioso para definir questões de avaliação, interpretar dados, emitir juízos de valor e planear respostas adequadas a esses mesmos dados. A questão fundamental neste processo é o compromisso das partes envolvidas no sentido de deixar de lado interesses mesquinhos, possibilitando a deliberação através da conversação, respeito e reciprocidade. ${ }^{5}$ Desta forma, "o conhecimento legítimo é ampliado para incorporar pontos de vista de grupos que têm menos poder" (Ryan, op. cit, p. 3). Em congruência, acrescenta esta autora, as metodologias mais adequadas para uma avaliação democrática deliberativa são diversas e mistas, incluindo, entre outros, os grupos de discussão e os fóruns públicos. Como lembram Howe e Ashcraft (2005), sendo difícil perceber onde termina a inclusão e começa o diálogo, também é difícil perceber onde termina o diálogo crítico e começa a deliberação. Por outro lado, estes mesmos autores sublinham que a forma como o diálogo é estruturado e 
a forma como é permeado pela informação disponível são dimensões importantes para determinar se ele é efetivamente deliberativo ou não. As conclusões devem ser baseadas em evidências, requerendo cooperação, concessões mútuas e benefícios partilhados. Neste sentido, a abordagem democrática deliberativa "atenua as desigualdades de poder entre os grupos interessados". Todavia, há que considerar assimetrias entre diferentes grupos, em termos de conhecimento, acesso à informação e maior facilidade com determinadas práticas discursivas, não sendo, por isso, muito fácil abrir mão das vantagens estratégicas. Ainda assim, "seria cínico pensar que as pessoas nunca podem ou nunca desejam abraçar os princípios da igualdade”.

Assumido por alguém preparado para ser mediador nesse diálogo, o papel do avaliador é essencial para garantir que o princípio da deliberação possa ser bem concretizado (Howe \& Ashcraft, 2005). Como escreve também Ryan, a deliberação é definida como o exercício de um raciocínio reflexivo sobre questões relevantes, incluindo a identificação de valores e preferências de todos os grupos interessados. Neste caso, é essencial que o avaliador promova um sentido democrático de justiça, tenha capacidade para mediar conflitos e gerir grupos, e esteja preparado para tomar posições sobre questões políticas e morais (Ryan, 2005). Se forem tidos em consideração estes princípios, bem como outras formas de avaliação democráticas, "não há nada de errado com a accountabilty - accountability serve o interesse público" (Ryan, 2004, p. 456).

Mas para além da avaliação, a accountability sustenta-se também em outros pilares (a prestação de contas e a responsabilização). E se a "avaliação pública", quando prevê processos de decisão coletiva, "supõe critérios e valores públicos" (House, 1994, p. 171), o mesmo deverá acontecer em relação à prestação de contas e à responsabilização. Relativamente ao pilar da prestação de contas, é importante salientar duas das suas componentes mais importantes - a informação e a justificação. Sobre estas componentes, um importante desafio na construção de uma configuração democraticamente avançada de accountability prende-se necessariamente com a mobilização das teorias críticas sobre os processos de informação e as práticas de argumentação. Neste particular, são aqui evidentes as interfaces com os princípios da avaliação democrática deliberativa, nomeadamente no que diz respeito ao "diálogo crítico".

Finalmente, dos três pilares estruturantes de uma configuração de accountability, o pilar da responsabilização parece ser o menos justificado em termos éticos, políticos e teórico-concetuais, apesar de, paradoxalmente, ser também o mais referenciado. É, aliás, disso exemplo a forma simplificada, superficial e redutora como a responsabilização tem sido propagandeada nos discursos vulgares. E esse facto, do meu ponto de vista, não é indiferente à natureza mais impositiva e mais autoritária como têm sido apresentadas (na forma e no conteúdo) muitas das decisões políticas para a educação e a formação nas últimas décadas. 
Neste contexto, invariavelmente, a responsabilização assume uma forte conotação negativa e culposa em termos discursivos e de representação social, e é congruente com a obsessão managerialista (ou gestionária) direcionada para impor determinados procedimentos e práticas que visam resultados visíveis e mensuráveis, sem preocupação com a politicidade dos objetivos, a complexidade dos processos organizacionais e a subjetividade dos atores. Neste sentido, parece-me plausível supor que, quando predomina a fórmula tecnocrática one best way, a responsabilização dos indivíduos tenderá a ser a consequência imediata e funcional de uma eventual fuga ou desvio à racionalidade instrumental que configura determinadas práticas de gestão. Assim, a responsabilização é mais facilmente reduzida à ameaça ou imputação negativa de culpa sobre determinadas acções e seus supostos resultados. Na visão de Stephen Ball, seguindo a linha crítica de Foucault, trata-se de uma "tecnologia moral" congruente com um sistema panóptico de vigilância e de poder que se exerce sobre os indivíduos no contexto das organizações, como as escolas (cf. Ball, 1990).

$\mathrm{E}$, tendo em conta a atual hegemonia dos valores neoconservadores e neoliberais, quando se equaciona a questão da responsabilização é difícil percebê-la ou imaginá-la sem que a sua frequente conotação negativa acabe por contaminar e envolver, igualmente de forma negativa, a própria concetualização de accountability no seu todo. Isto, aliás, também impede ou dificulta o desenvolvimento de um pensamento crítico proponente (ou proposicional) em torno de outras concetualizações e práticas alternativas de accountability.

Na minha perspectiva, algumas dificuldades têm a ver com a utilização, muitas vezes sincrética e intercambiável, dos conceitos de responsabilidade e de responsabilização, bem como com a representação e usos sociais da ideia de culpa que the está associada. Por estas e outras razões, sinto necessidade de pontuar aqui alguns aspetos, salientando desde logo como pertinente a distinção entre responsabilidade e culpa.

Para Hannah Arendt, por exemplo, "há uma responsabilidade por coisas que não fizemos; podemos ser considerados responsáveis por elas. Mas não há um ser ou considerar-se culpado por coisas que aconteceram sem que se tenha participado ativamente delas" (Arendt, 2004, p. 213-214). E, mais à frente, acrescenta: "A culpa, ao contrário da responsabilidade, sempre seleciona, é estritamente pessoal. Refere-se a um ato, não a intenções ou potencialidades" (p. 214). Posteriormente, a contribuição de Iris Young é, neste particular, também importante porque, apesar de esta autora não ter podido desenvolver até ao fim a sua argumentação, deixou-nos uma preocupação teórico-concetual, ética e política quando, na esteira de Arendt, propôs que pensássemos a responsabilidade separada da culpa. No confronto com perspetivas diferentes, a autora defende que a responsabilidade não é sempre individual, como alguns autores pretendem, mas é essencialmente coletiva (Young, 2011). 
Isto tem grande pertinência e atualidade porque pode contrariar a razão do crescente apelo responsabilizador em relação à iniciativa individual, sobretudo quando se abandona o homem à sua sorte e ao seu destino, perante a retração do Estado e a apregoada incapacidade deste para continuar a zelar pelo bem comum. Numa época como a que hoje vivemos, não é por acaso que os defensores da responsabilidade e da responsabilização individuais são, sobretudo, os neoconservadores e neoliberais, os quais, coincidentemente, tendem a ser os mesmos que criticam as políticas públicas (universais) do Estado-providência. Sem negar as dimensões individuais, Young (op. cit.) chama à atenção, todavia, para a existência de muitos fatores que não resultam da ação ou da vontade individual e que estão na origem do que designa de "injustiça estrutural". Dito de outro modo, as pessoas estão inseridas num contexto de múltiplas interações, e não se podem abstrair os fatores relacionais e contextuais quando se consideram essas ações. Por isso, segundo a autora, a responsabilidade é partilhada.

Como exercício exemplificativo, transponha-se a perspetiva de Young para o contexto de uma escola pública onde estudam alunos de diferentes grupos e classes sociais. Se essa escola se constituir como lugar de reprodução social e cultural e de legitimação das desigualdades (Bourdieu \& Passeron, 1970), podemos dizer que aí se produzem injustiças várias. Neste aspeto, independentemente da ação concreta de cada professor(a), individualmente considerado(a), todos os(as) professores(as) dessa escola são responsáveis, na medida em que, de forma direta ou indireta, participam de processos estruturais e organizacionais que têm consequências injustas. Do meu ponto de vista, a consideração e interiorização destes argumentos far-nos-ia retomar a ideia de um trabalho coletivo, reflexivo e mais comprometido, contribuindo para acabar com a crescente fragmentação (solipsista) do ser humano (também professor ou professora) nas sociedades capitalistas em crise profunda.

\section{Em síntese}

Ao concluir, provisoriamente, este texto, reitero os pressupostos que considero mais pertinentes: a accountability não é uma problemática política, social e educacional que deva continuar capturada ou confinada, por alguma razão natural ou supostamente intrínseca, a perspetivas ideológicas e práticas governativas neoconservadoras ou neoliberais. Procurei, por isso, deixar aqui algumas ideias, para um aprofundamento futuro, que permitam complexificar a análise e convocar caminhos teórico-concetuais capazes de sustentar uma configuração mais democrática, mais justa e mais dialógica de accountability. Se a avaliação, a prestação de contas e a responsabilização não podem nem devem ser desligadas do aprofundamento da própria democracia, não é qualquer concetualização de accountability que pode ser 
congruente com essa mesma democracia, sobretudo quando for concebida de forma mais avançada (por exemplo, como democracia deliberativa) e como projeto político, cultural e ético mais capaz de fazer face aos desafios do mundo contemporâneo.

\section{Notas}

1. No que diz respeito ao Brasil, é muito importante registar o facto de estar em construção e consolidação um Movimento Contra os Testes de Alto Impacto na Educação. Disponível em: <http:// sites.google.com/site/movimentocontratestes/> Acesso: em 29 abr. de 2012.

2. Em um elucidativo artigo no jornal Guardian, intitulado "No merit in merit pay for teachers", em que se sinaliza diacronicamente alguns momentos importantes no debate sobre o pagamento na base do mérito, Walt Gardner (2011) começa por escrever: "The latest fad in education is performance-related pay. It didn't work in England in the 1700s, and it doesn't work in the US now". E conclui: "It's highly unlikely, however, that evidence amassed over the years will finally put and end to teacher incentive plans. Educational outsiders have the luxury of not having to live with the consequences of their delusions".

3. Há, todavia, estudos que mostram aspetos quer positivos quer negativos destas medidas. A este propósito, com referência à Inglaterra, ver, por exemplo, Atkinson et al. (2004).

4. Como este mesmo documento explicita, "Governance means rules, processes and behaviour that affect the way in which powers are exercised at European level, particularly as regards openness, participation, accountability, effectiveness and coherence" (2001, p. 8).

5. Todavia, como lembra Ernest House (1994, p. 174), “Todo diálogo supone la reciprocidad de conciencias entre los participantes, pero la reciprocidad puede darse entre el amo y su esclavo o entre un jefe y sus súbditos. Estas relaciones son recíprocas, pero desiguales. La consecución de la comunidad racional no sólo requier diálogo, sino que éste sea entre iguales. El diálogo libre exige la réplica sin cortapisas. Las relaciones de poder deforman el diálogo".

\section{Referências}

AFONSO, A.J. Estado, mercado, comunidade e avaliação: esboço para uma (re)articulação crítica. Educação E Sociedade, Campinas, v. 20, n. 69, p. 139-164, 1999.

AFONSO, A.J. Nem tudo o que conta é mensurável ou comparável: crítica à accountability baseada em testes estandardizados e rankings escolares. Revista Lusófona de Educação, Lisboa, n. 13, p. 13-29, 2009.

AFONSO, A.J. Um olhar sociológico em torno da accountability em educação. In: ESTEBAN, M.T.; AFONSO, A.J. (Org.). Olhares e interfaces: reflexões críticas sobre a avaliação. São Paulo: Cortez, 2010a., p. 147-170.

AFONSO, A.J. Gestão, autonomia e accountability na escola pública portuguesa: breve diacronia. Revista Brasileira de Política e Administração da Educação, Porto Alegre, v. 26, n. 1, p. 13-30, 2010b.

AMIN, S. O vírus liberal. Porto: Campo das Letras, 2005. 
ARENDT, H. Responsabilidade e julgamento. São Paulo: Cia das Letras, 2004.

ATKINSON, A. et al. Evaluating the impact of performance-related pay for teachers in England. Bristol: University of Bristol; Centre for Market and Public Organization, 2004.

BALL, S. Management as moral technology: a Luddite analysis. In: BALL, S.J. (Ed.). Foucault and education: disciplines and knowledge. New York: Routledge, 1990. p. 153-166.

BOURDIEU, P.; PASSERON, J.-C. La reproduction. Paris: Minuit, 1970.

CARVALHO, L.M. (Org.). O espelho do perito: inquéritos internacionais, conhecimento e política em educação - o caso do Pisa. Porto: FML, 2011.

COMMISSION OF THE EUROPEAN COMMUNITIES. European governance: a white paper. Brussels: CEC, 2001. Disponível em: <http://eur-lex.europa.eu/LexUriServ/ site/en/com/2001/com2001_0428en01.pdf>. Acesso em: 29 abr. 2012.

COSTA, E. O "Programme for International Student Assessment" (Pisa) como instrumento de regulação das políticas educativas. 2011. Tese (Doutorado em Educação) - Instituto de Educação, Universidade de Lisboa, Lisboa.

ESTEBAN, M.T.; AFONSO, A.J. (Des)qualificando e requalificando as qualidades da educação: entre o comparativismo acrítico e as aprendizagens emancipatórias. In: LEITE, C. et al. (Org.). Debater o currículo e seus campos: politicas, fundamentos e práticas; actas do 9. Colóquio sobre Questões Curriculares/5. Colóquio Luso-Brasileiro, 2010, Porto. Braga: Cied, 2010. p. 205-214.

EURYDICE. School autonomy in Europe: policies and measures. Brussels: Eurydice, 2007.

EURYDICE. Exames nacionais de alunos na Europa: objectivos, organização e utilização de resultados. Lisboa: Ministério da Educação, 2010.

FREITAS, L.C. Qualidade negociada: avaliação e contra-regulação na escola pública. Educação \& Sociedade, Campinas, v. 26, n. 92, p. 911-933, 2005.

FREITAS, L.C. A eliminação adiada: o caso das classes populares no interior da escola e a ocultação da (má) qualidade do ensino. Educação \& Sociedade, Campinas, v. 28, n. 100, p. 965-987, 2007.

GARDNER, W. No merit in merit pay for teachers. Guardian, London, 27 march 2011. Disponível em: <http://www.guardian.co.uk/commentisfree/cifamerica/2011/ mar/27/schools-teaching/print $>$. Acesso em: $1^{\circ}$ maio 2012.

HARLOW, C. Accountability in the European Union. New York: Oxford University, 2002.

HOUSE, E.R. Accountability in the USA. Cambridge Journal of Education, Cambridge, Mass., v. 5, n. 2, p. 71-78, 1975. 
HOUSE, E.R. Evaluación, ética y poder. Madrid: Morata, 1994.

HOWE, K.; ASHCRAFT, C. Deliberative democratic evaluation: successes and limitations of an evaluation of school choice. Teachers College Records, New York, v. 107, n. 10, p. 2275-2298, 2005.

NORMAND, R. Mercado, performance, accountability: duas décadas de retórica reaccionária na educação. Revista Lusófona de Educação, Lisboa, n. 11, p. 49-76, 2008.

PORTUGAL. Presidência do Conselho de Ministros. Programa do XIX Governo Constitucional. Lisboa, 2011. Disponível em: <http://www.portugal.gov.pt/media/130538/ programa_gc19.pdf $>$. Acesso em: $1^{\circ}$ maio 2012.

RANSON, S. Public accountability in the age of neo-liberal governance. Journal of Education Policy, London, v. 18, n. 5, p. 459-480, 2003.

RAVITCH, D. The death and life of the great American schools system: how testing and choice are undermining education. New York: Basic Books, 2010a.

RAVITCH, D. Volte-face de uma ministra americana. Le Monde Diplomatique, edição portuguesa, II série, n. 48, p. 9, $2010 \mathrm{~b}$.

RYAN, K. Serving public interests in educational accountability: alternative approaches to democratic evaluation. American Journal of Evaluation, v. 25, n. 4, p. 443-460, 2004.

RYAN, K. Democratic evaluation approaches for equity and inclusion. Evaluation Exchange, Cambridge, Mass., v. 11, n. 3, 2005. Disponível em: <http://www.hfrp.org/var/ $\mathrm{hfrp} /$ storage/original/application/86b58ecfa2fcabb5d74846ffb2edf284.pdf.> Acesso em: 26 abr. 2012.

SÁ, V. O discurso da qualidade no contexto da recomposição das desigualdades em educação. Revista Brasileira de Estudos Pedagógicos, Brasília, DF, v. 89, n. 223, p. 425-444, 2008.

SANTIAGO, P. et al. OECD reviews of evaluation and assessment in Education: Portugal 2012. [S.1.]: OECD, 2012.

STOBART, G. Tiempos de pruebas: los usos y abusos de la evaluación. Madrid: Morata, 2010.

YOUNG, I. Responsabilidad por la justicia. Madrid: Morata, 2011.

Recebido em 13 de maio de 2012.

Aprovado em 1 de junho de 2012. 